\title{
Estratégia para a redução da pobreza no estado no Rio de Janeiro: algumas reflexões sobre o Plano Rio Sem Miséria
}

\author{
Strategy for reducing poverty in the state of Rio de Janeiro: some reflections on the Rio \\ plan without misery \\ Angélica Cristina Nagel Hullen* \\ Márcio Eduardo Brotto**
}

\begin{abstract}
Resumo:
Este artigo resulta da pesquisa desenvolvida no mestrado em Serviço Social na Pontifícia Universidade Católica do Rio de Janeiro - PUC/RJ que tem como objetivo de realizar uma análise do Plano Rio Sem Miséria e sua contribuição para a redução da pobreza no RJ. Parte-se da premissa de que o Brasil tem se destacado no período recente pela redução da pobreza, especialmente a extrema pobreza. $O$ crescimento econômico e a inclusão social são fatores preponderantes para esta redução. Em 2011 foi lançado o Plano Brasil Sem Miséria com o objetivo de reduzir a extrema pobreza no país até 2014. Alinhado à estratégia federal e mediante o cenário de pobreza presente no estado, o Rio de Janeiro cria seu plano de superação da pobreza, com vistas à proteção social, o Plano Rio Sem Miséria.
\end{abstract}

Palavras-chave: Pobreza; Política social; Proteção social; Plano Rio sem miséria; Rio de Janeiro.

\begin{abstract}
:
This article result of research carried out in the master's degree in social work at the Catholic University of Rio de Janeiro - PUC / RJ that aims to perform an analysis of the Rio plan without misery and its contribution to poverty reduction in RJ. It starts with the premise that the Brazil has excelled in, the recent period, the reduction of poverty, especially extreme poverty. Economic growth and social inclusion are crucial factors for this reduction. In 2011, it launched the Brazil without Poverty Plan with the goal of halving extreme poverty in the country by 2014. Aligned federal strategy and through this scenario in the State poverty, Rio de Janeiro creates his plan for overcoming poverty, with a view to social protection, the Rio plan without misery. This research aims to conduct an analysis of PRSM and its contribution to reduction poverty in RJ.
\end{abstract}

Key-words: Poverty; Social policy; Social protection; Rio plan without misery; Rio de Janeiro.

\footnotetext{
* Assistente Social. Mestre em Serviço Social pela PUC/RJ e Doutoranda do Programa de Pós-Graduação em Serviço Social da PUC/RJ. E-mail: angelica.hullen@hotmail.com

** Assistente Social. Mestre e doutor em serviço social pela PUC/RJ. Professor do Programa de PósGraduação em Serviço Social da PUC/RJ E-mail: meb.brotto@uol.com.br
} 


\section{Introdução}

O Brasil tem se destacado, no período recente, pela redução da pobreza, especialmente a extrema pobreza. Este resultado deve-se a um conjunto de fatores que vão desde a recuperação do salário mínimo, passando pela crescente incorporação de trabalhadores no mercado formal de trabalho, com o aumento do número de empregos, até a consolidação do Programa Bolsa Família - PBF e do Sistema Único de Assistência Social-SUAS.

O PBF tem apresentado efeitos consistentes na redução da pobreza e da desigualdade entre os grupos mais vulneráveis: crianças, adolescentes, gestantes e nutrizes. O Programa proporcionou ainda o aumento da escolarização na faixa etária de 7 a 17 anos, aumento do nível de vacinação em crianças menores de 5 anos e o aumento do acesso ao atendimento pré-natal (BRASIL, 2014).

Juntamente com o PBF, o país implantou o SUAS, que busca integrar as políticas de Assistência Social num modelo racional, equitativo, descentralizado, participativo e com financiamento compartilhado entre os entes federados. O SUAS é um sistema público, não contributivo, que tem por função a gestão e a organização da oferta de benefícios e serviços da assistência social.

A convergência entre os benefícios e os serviços da Assistência Social proporcionou avanços no que se refere à superação da pobreza: foram mais de 28 milhões de pessoas que saíram da situação de pobreza extrema, no entanto, mesmo diante dos resultados, 16,2 milhões de pessoas permaneceram nessa condição (IBGE, 2010), demonstrando que as políticas públicas implementadas não foram suficientes e mostraram-se de difícil acesso para as camadas mais pobres da população, sendo incapazes de reverter esta situação. Neste contexto, o governo da Presidente Dilma Rousseff, ciente da limitação da política aplicada, apresenta o Plano Brasil Sem Miséria (PBSM) em junho de 2011, com o objetivo de erradicar a extrema pobreza monetária no Brasil até o final de 2014. No mesmo momento, conclama os governos subnacionais a criarem seus planos de superação da pobreza.

Alinhado à estratégia do governo federal e mediante um cenário de pobreza e desigualdade, o governo do Estado do Rio de Janeiro criou o Plano Rio Sem Miséria - PRSM, que consiste no Plano Estadual de Superação da Pobreza, composto pelo Programa Renda 
Melhor (PRM), Programa Renda Melhor Jovem (PRMJ), Gestão de Oportunidades Sociais e Econômicas (GOES) e a estratégia de Fortalecimento do Sistema Único de Assistência Social (SUAS) e o Acompanhamento Familiar.

O objetivo desta pesquisa consiste em realizar uma descrição sistemática do Plano Rio Sem Miséria e das suas estratégias e resultados iniciais para a redução da pobreza no Estado do Rio de Janeiro, com vistas a construção de uma política de proteção social no estado.

Para atingir os fins a que se propõe esta pesquisa, realizamos um estudo de caso, análise de dados quantiqualitativos, entrevistas com gestores (elaboradores e executores) do Plano Rio Sem Miséria na esfera estadual e acompanhamento de alguns eventos (como, por exemplo, reuniões com gestões municipais, com parceiros do Plano, com parceiros privados e reuniões mensais da Comissão Intergestores Bipartite - CIB do Estado do Rio de Janeiro).

\section{Breves reflexões sobre a temática da proteção social}

Os sistemas de proteção social sempre existiram nas sociedades humanas, com vários estudos nas áreas de história, antropologia, sociologia, entre outras, que comprovam a existência da solidariedade social nas sociedades mais tradicionais, modernas e contemporâneas.

O autor Di Giovanni (1998) afirma que as sociedades sempre alocaram recursos e esforços em suas atividades de proteção social, podendo variar de acordo com os critérios históricos e culturais e ser classificadas em: tradicional (referente à caridade, fraternidade e solidariedade); da troca (conjunto de práticas econômicas, que podem ser face a face ou relacionadas ao mercado); e ainda da autoridade ou da políticas (presença do estado como gestor, regulador e protetor das relações sociais). Esta classificação não tem o caráter evolucionista, visto que as três formas de proteção citadas pelo autor perduram no contexto atual, assim como coexistem. Porém, na contemporaneidade há a predominância das formas de proteção social exercidas pelo Estado, alocadas politicamente.

A intervenção do Estado, com a formação de ações sociais não mercantis, tem origem nas sociedades tradicionais para impedir ou diminuir o impacto de determinados riscos sobre indivíduos e grupos sociais. As primeiras populações, que foram objeto de 
intervenção social do Estado, de acordo com Castel (1998) foram aquelas identificadas como não capacitadas ao exercício do trabalho, tais como órfãos, mulheres com filhos pequenos, inválidos, idosos e indigentes, ou seja, populações submetidas a grandes situações de vulnerabilidades e isentas da obrigação do trabalho, que se constituíram no público legítimo para os recursos e serviços públicos.

Porém, a consolidação dos Sistemas de Proteção Social não ocorreu no âmbito das situações de incapacidade e independência, "passando a exercer papel central e estratégico nas sociedades modernas" (JACCOUB; CARDOSO JUNIOR, 2010, p.104) e sim em torno do conceito de risco social que a intervenção pública passou a ser construída, por meio da observação das transformações ocorridas no mundo do trabalho e as vulnerabilidades a ele associadas, cuja reponsabilidade até então era da esfera privada e estava centrada na proteção do trabalhador.

Os riscos sociais podem ser compreendidos como aqueles relacionados a fatores que podem incidir sobre grupos ou indivíduos, tais como: doença, velhice, infância, invalidez etc. E, embora estivessem associados a condições naturais e/ou ambientais, são oriundos, quase sempre de fatores políticos, sociais ou culturais (VIANA; LEVCOVITZ, 2005).

Com o crescimento da industrialização, no final do século XIX, percebe-se a pobreza como problema efetivo das sociedades, com centralidade no debate sobre a proteção social. A condição do trabalhador assalariado e os fenômenos da limitação ao trabalho passam a ser vistos como parte presente e pertencente da vida social e laboral, assim como regulares e cotidianas.

Na segunda metade do século XX, temos a mudança na organização dos sistemas de proteção social, especialmente nos países desenvolvidos, que passam a ter centralidade nos trabalhadores e nos cidadãos. Observamos, nesse contexto, a emergência dos programas não contributivos de garantia de renda, ao lado da rápida expansão dos serviços sociais de acesso universal, instaurando um novo modelo de intervenção do Estado.

Os benefícios sociais passaram a ser garantidos nas demandas para a melhoria das condições sociais de grupos vulneráveis e de garantias de bem-estar associadas à cidadania. Esping-Andersen (1991) cita a Alemanha, a Inglaterra e a Suécia, entre outros países, em seus estudos, como países que instituíram seguro universal baseados em contribuições não contributivas ou em contribuições uniformes, garantindo benefícios iguais, visando 
assegurar um mínimo vital a todos os cidadãos, destacando-se os países conhecidos como o modelo beveridgiano ${ }^{1}$. Nesses casos, houve a ampliação dos gastos sociais por parte do Estado, em contrapartida houve o aumento da universalização dos serviços de saúde, creches e cuidados a pessoas idosas ampliados, bem como a expansão dos programas de garantia de renda não contributivos para a infância e a habitação.

Porém, nas décadas de 1980 e 1990, com as alterações no cenário do mundo do trabalho e o acirramento da competitividade das economias no mercado internacional, a trajetória da expansão dos Estados Sociais ou "Welfare States" passou a ser colocada sobre forte crítica: excessiva expansão dos direitos sociais e excessiva participação do Estado e do gasto público ${ }^{2}$ no campo social. Questionava-se também, neste momento, o papel dos governos no campo da proteção social, caracterizando-os como desnecessários e mesmo ineficientes.

Neste contexto, de acordo com Jaccoub e Cardoso Junior (2010), a proteção contra os riscos deveria ser responsabilidade prioritária dos indivíduos e objeto da ação do mercado, pelos regimes capitalizados e geridos pelo mercado, ou da própria sociedade por meio dos movimentos voluntários. "Nesta nova interpretação, a pobreza se destaca como um fenômeno social específico, legitimador da ação do Estado" (JACCOUB; CARDOSO JUNIOR, 2010, p. 107).

Quando o debate sobre a temática recai sobre os países em desenvolvimento, o Banco Mundial (1995), por meios de seus relatórios, centraliza o debate conceitual no combate à pobreza indicando que os pobres deveriam estar inseridos em estratégias governamentais com o envolvimento do setor público e privado, visando o fortalecimento das suas capacidades e objetivando a prevenção de acontecimentos aleatórios (gestão de riscos). Já com relação aos extremamente pobres, o Estado é incapaz de mobilizar estratégias individuais de proteção social, em que somente seriam cabíveis as políticas de transferência de renda.

\footnotetext{
${ }^{1} \mathrm{O}$ economista e reformista social britânico William Henry Beveridge (1879-1963) elaborou em 1942 o Reporton Social Insurance and Allied Services, famoso Plano Beveridge, visando libertar o homem da necessidade. Propôs, assim, que todas as pessoas em idade de trabalhar deveriam pagar uma contribuição semanal ao Estado. Esse dinheiro seria posteriormente usado como subsídio para doentes, desempregados, reformados e viúvas. Os subsídios deveriam então tornar-se um direito dos cidadãos, em troca de contribuições, em vez de pensões dadas pelo Estado.

2 Compreendia-se que este gasto deveria ser responsabilidade das empresas.
} 
Outro conceito importante relacionado à proteção social e muito utilizado atualmente baseou-se na discussão efetuada pela Comissão de Estudos para a América Latina-CEPAL, enfatizando a necessidade da proteção social estar baseada na perspectiva dos direitos sociais, em função do mercado de trabalho, que há muito tempo na América Latina e Caribe vem sofrendo grandes mudanças por causa da precarização, flexibilização e desemprego estrutural, e não vem mostrando com isso capacidade abrangente de proteger a parcela significativa da população dos riscos relacionados à falta de renda, saúde e envelhecimento.

A ideia defendida pela CEPAL consiste na adoção de um sistema de transferência que se propõem a oferecer proteção contra os riscos sociais, combinando mecanismos contributivos e não contributivos (auxílios financeiros dos programas assistenciais por meios das transferências diretas de renda) e transferências de bens e serviços (como, por exemplo, os serviços universais de saúde).

A adoção de um sistema de transferência também é defendida por Draibe (1993), porém a partir de uma perspectiva que preconiza apenas o mecanismo não contributivo. De acordo com a autora, o sistema precisa combinar transferências diretas de renda não contributivas com as transferências de bens e serviços sociais, sobretudo paras as famílias brasileiras que estão abaixo da linha de pobreza, que além da insuficiência de renda quase sempre não têm as suas necessidades vitais satisfeitas, ou seja, não tem acesso à escola pública de qualidade, à saúde pública de qualidade etc.

É nesse contexto que o Estado passa a ser responsável prioritário pela garantia dos direitos sociais e da proteção social, por meio da execução das políticas públicas, cuja materialização são os programas, planos e ações. Nesse cenário, tem destaque, em vários países, especialmente no Brasil, a implantação de Programas de Transferência de Renda com Condicionalidades como principal forma de garantia de proteção social às populações mais vulneráveis.

O desenvolvimento de políticas sociais com o objetivo de proteger os pobres é antigo, existindo desde as sociedades pré-capitalistas e precede o surgimento de dois movimentos que são o fundamento da questão social, surgida no século XX: a economia de mercado e a reação da classe trabalhadora aos efeitos perversos dessa economia de mercado (PEREIRA, 2000). 


\section{Antecedentes do Plano Rio Sem Miséria}

A referência de que a pobreza e a desigualdade no Brasil seriam combatidas paulatinamente com o avanço do progresso e do desenvolvimento econômico, o tema apesar de não estar ausente das preocupações e reflexões do país sobre o seu futuro, conforme observou Telles (1998) - era visto como elemento quase imutável, permanente e tinha caráter secundário, não merecendo tratamento específico.

A partir da década de 1980, especialmente com o processo de redemocratização do país, o tema passou a fazer parte das discussões e reinvindicações, especialmente dos movimentos populares e esta preocupação é materializada na $\mathrm{CF} / 88$, quando ocorreu a alteração da percepção de pobreza, que passou a ser preocupação estatal, quando a lei maior do país passa a prever no art. 23, inciso X, que é "competência dos entes federados combater as causas da pobreza e os fatores de marginalização promovendo a integração social dos setores desfavorecidos" (BRASIL, 1988).

Podemos afirmar que no debate atual sobre a questão da pobreza no Brasil, contemplamos dois consensos: a) que ela é um fenômeno estrutural de nossa sociedade; e b) que o principal fator de sua persistência está na desigualdade social, que, uma vez, não combatida tende a reproduzir essa desigualdade. Outro consenso é de que a pobreza no Brasil segue uma trajetória particular, continuando a ser um problema social a ser enfrentado pelo Estado, independentemente das formas como aparece e se manifesta na sociedade.

Alguns fatores podem ser considerados como relevantes para a ampliação do processo de proteção social no Brasil, tendo como consequência a redução da pobreza e da desigualdade. Entre eles podemos citar a consolidação do SUAS, a criação do Programa Bolsa Família e, em 2011, a implatanção do Plano Brasil Sem Miséria- PBSM, que potencializou algumas ações que já vinham sendo desenvolvidas no país, reafirmando a ideia de que a pobreza e a proteção social são compromissos das diversas políticas públicas e não apenas da política de Assistência Social.

Juntamente como o PBSM, o governo federal pactua com os governos subnacionais a criação de Programas próprios de combate à pobreza, reforçando as premissas estabelecidas na Constituição Federal de 1988, bem como enfatizando o compromisso da 
criação de programas que têm como objetivo a ampliação e a garantia da proteção social para os cidadãos, em especial aqueles em situação de risco e de vulnerabilidades sociais.

Para compreender essa processo, é necessário traçarmos, brevemente, os principais antecedentes do PRSM, considerando a sua devida relevância.

\section{A consolidação do Sistema Único de Assistência Social - SUAS}

A preocupação estatal, a mobilização e participação social encontram-se materializadas na $\mathrm{CF} / 88$, quando a política de Assistência Social passa a compor o tripé da seguridade social, juntamente com a saúde e com a previdência social e deve ser compreendida como dever do Estado e direito do cidadão. Nesse cenário ocorre a implantação e consolidação do Sistema Único de Assistência Social (SUAS) e da Política Nacional de Assistência Social (PNAS), e a criação do maior programa de transferência de renda do Brasil, o Programa Bolsa Família (PBF), com vistas a superação da pobreza no país.

O modelo de política pública de Seguridade Social não contributiva, voltada ao cidadão que dela necessitar, supera o modelo de concepção restritiva, de seguro adotado no país e a lógica de mercado, alcançando os cidadãos que dificilmente acessam serviços públicos pela sua condição de extrema vulnerabilidade que não têm seus direitos garantidos, assim como os benefícios advindos do mercado de trabalho. Sposati et al. (2009) afirma que a proteção social não contributiva nasce do direito de preservação à vida e do respeito à dignidade humana, expresso nos direitos fundamentais inscritos na Constituição Federal.

O SUAS busca integrar as políticas de Assistência Social em um modelo racional, equitativo, descentralizado, participativo e com o financiamento compartilhado com os entes federados - União, estados, Distrito Federal e os municípios. É um sistema público não contributivo, que tem por função a gestão, a organização da oferta de benefícios e serviços da política de Assistência Social de acordo com os níveis de proteção social: básica, especial de média e alta complexidade. Em 2014 (Censo SUAS/MDS), a rede de Assistência Social possuía mais de 10 mil equipamentos e mais de 232 mil trabalhadores com vários níveis de formação.

\section{Programa Bolsa Família}

Criado em 2003, o PBF é o resultado da unificação de programas sociais de transferência de renda já existentes (Bolsa Escola, Bolsa Alimentação, Vale Gás e Cartão 
Alimentação). Foi regulamentado pela Lei n ${ }^{\circ} 10.836 / 2004$ e, posteriormente, por uma série de decretos e instrumentos infralegais.

É um programa de transferência de renda focalizado, ou seja, destinado às famílias que estão na situação de extrema pobreza (renda per capita mensal de até $R \$ 77,00$ ) e de pobreza (renda per capita mensal de $\mathrm{R} \$ \mathbf{7 7 , 0 1}$ até $\mathrm{R} \$ \mathbf{1 5 4 , 0 0 )}$ ), com condicionalidades, tendo como objetivos: i) a curto prazo, o alívio imediato da pobreza por meio da transferência de renda; ii) a médio prazo, a ruptura do ciclo intergeracional da pobreza, por meio do acesso aos serviços básicos de saúde, educação e assistência social, que se materializa no cumprimento das condicionalidades do Programa; iii) a longo prazo, o desenvolvimento integral das famílias.

Atualmente, de acordo com o MDS (BRASIL, 2014), mais de 13 milhões de famílias são beneficiárias do PBF, com o repasse mensal de mais de 2 bilhões de reais.

Outra característica importante do Programa é o fato de possuir condicionalidades, que se expressam em compromissos na área de saúde (vacinação em dia e pré-natal), educação (matrícula em estabelecimento de ensino e frequência acima de $85 \%$ para crianças e adolescentes de 6 a 15 anos) e assistência social (85\% de presença nas atividades socioeducativas do PETI).

Para que as famílias façam parte do Programa é necessário que elas sejam cadastradas no Cadastro Único, a partir disso são selecionadas por meio das informações no referido instrumento de cadastramento das famílias de baixa renda do governo federal.

Criado em 2001, este vem sendo aperfeiçoado e consiste no principal instrumento público nacional para a manutenção das informações atualizadas das famílias brasileiras com renda per capita mensal de até $1 / 2$ salário mínimo ou três salários mínimos mensais. 0 cadastro, utilizado pelas três esferas de governo, permite identificar os potenciais beneficiários para os programas sociais, buscando proporcionar melhor focalização e evitar a sobreposição de programas.

\section{Cenário econômico e social do Estado do Rio de Janeiro}

Vários indicadores podem ser utilizados para dimensionar os tipos e a magnitude da desigualdade social no Rio de Janeiro, sendo que neste momento não se trata de realizar um inventário detalhado das condições de vida da população, mas de fornecer um quadro 
sintético de algumas dimensões que traduzem aspectos de vulnerabilidade e de exclusão social.

Com uma área de $43.780,172, \mathrm{~km}^{2}$, o Estado do Rio de Janeiro representa $0,51 \%$ do território brasileiro. Seu território está dividido em 92 municípios, distribuídos em oito regiões de governo: Metropolitana, Noroeste Fluminense, Norte Fluminense, Serrana, das Baixadas Litorâneas, do Médio Paraíba, Centro Sul-Fluminense, da Costa Verde (CEPERJ, 2014).

Figura 1 - Mapa político do Estado do Rio de Janeiro

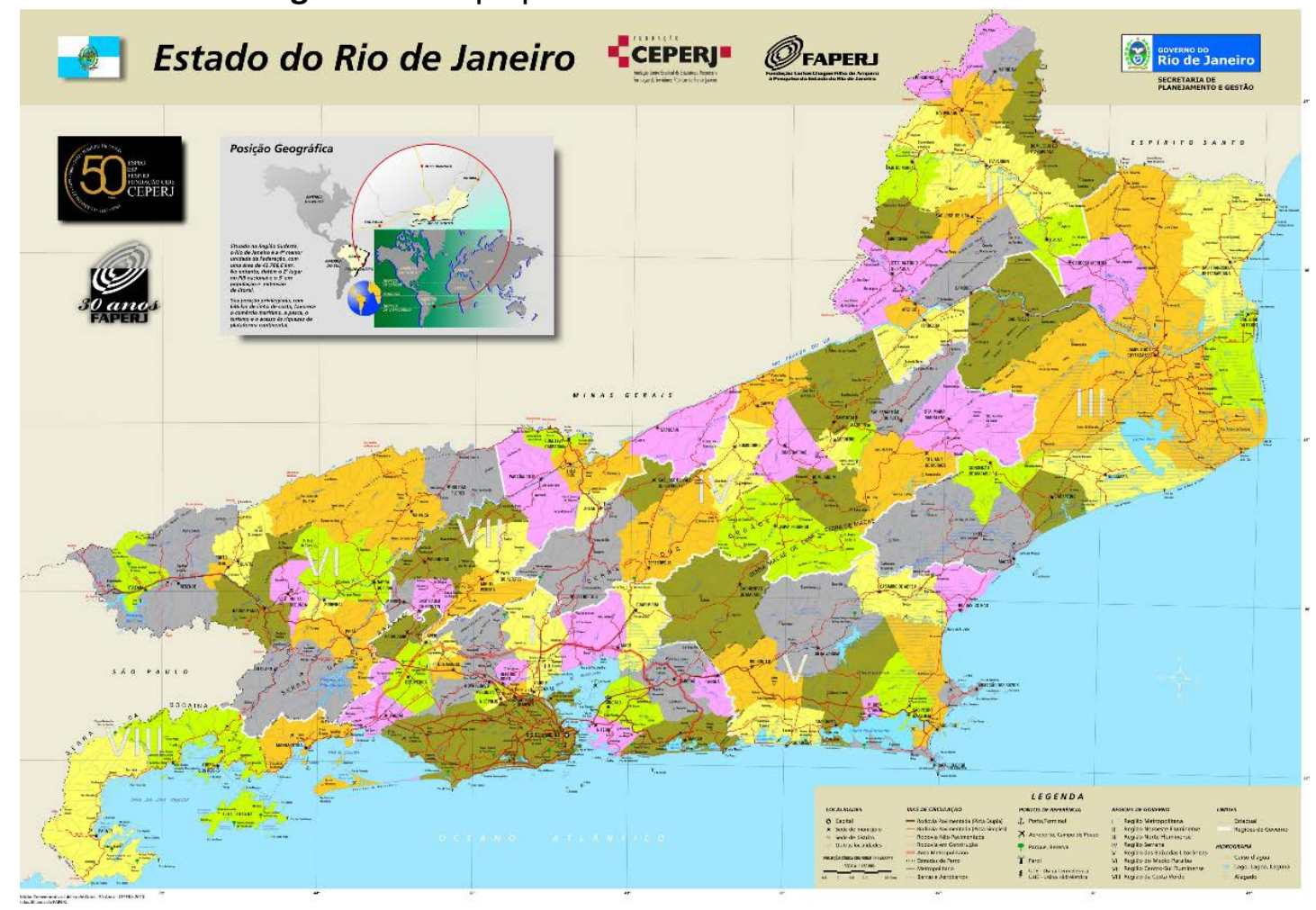

Fonte: CEPERJ (2014).

Em 2013, a população do Estado chegou a 16.369.178 habitantes, sendo que a maior parte desse contingente populacional encontra-se na Região Metropolitana $(73,7 \%)$ e em áreas urbanas, visto que, em $2010,96,7 \%$ da população residia nessas áreas. Entre as regiões do estado, a Metropolitana foi a que apresentou a maior taxa de urbanização $(99,5 \%)$, e a Noroeste Fluminense foi a que apresentou a menor taxa (82,6\%). Como informação relevante, além dos dados sobre a população é importante destacar que o Rio de Janeiro é a segunda unidade da federação em termos de PIB (R\$ 462.376 milhões), 
sendo que este indicador apresentou em 2011 o crescimento real de 2,1\% inferior ao de 2010, que foi de 4,5\% (CEPERJ, 2014).

Além dos dados acima, é o primeiro estado colocado no cenário nacional no que se refere à geração de empregos no ano de 2012, nos meses de novembro e dezembro. Segundo os dados do Cadastro Geral de Empregados e Desempregados, divulgados pelo Ministério do Trabalho, foram gerados 14.051 empregos com carteira assinada em novembro, é a maior marca do mês entre todos os estados brasileiros, com expansão de 0,36\% em relação ao mês anterior. Essa geração de empregos vem sendo uma constante nos anos de 2011 e 2012.

Observa-se que a economia do estado fluminense apresenta-se em constante ascensão com geração de emprego e renda. Mas mesmo diante deste cenário, podemos afirmar que o ele tem na desigualdade de renda uma das suas matrizes mais marcantes e que se configura como um dos principais desafios norteadores para a implantação das políticas públicas de acordo com as entrevistas realizadas com os formuladores e gestores do Plano Rio Sem Miséria, especialmente no que se refere à área da Assistência Social, conforme veremos pelos dados apresentados a seguir.

De acordo com os estudos realizados pelo IPEA e FGV, observa-se na última década que enquanto nos outros estados da região sudeste o índice de Gini $^{3}$ segue em uma tendência de queda no Rio de Janeiro o índice permanece estagnado, demonstrando que o crescimento econômico não acarreta a justa distribuição de renda e na redução das desigualdades, conforme podemos observar a seguir.

\footnotetext{
${ }^{3} \mathrm{O}$ Coeficiente de Gini é utilizado para calcular a desigualdade de distribuição de renda de qualquer distribuição. Ele consiste em um número entre 0 e 1 , em que 0 corresponde à completa igualdade de renda ou rendimento (onde todos têm a mesma renda) e 1 corresponde à completa desigualdade (onde uma pessoa tem toda a renda ou rendimento, e as demais nada têm). 0 índice de Gini é o coeficiente expresso em pontos percentuais (é igual ao coeficiente multiplicado por 100).
} 
Gráfico 1- Comparativo da evolução do índice de Gini entre Rio de Janeiro, São Paulo e a região Sudeste

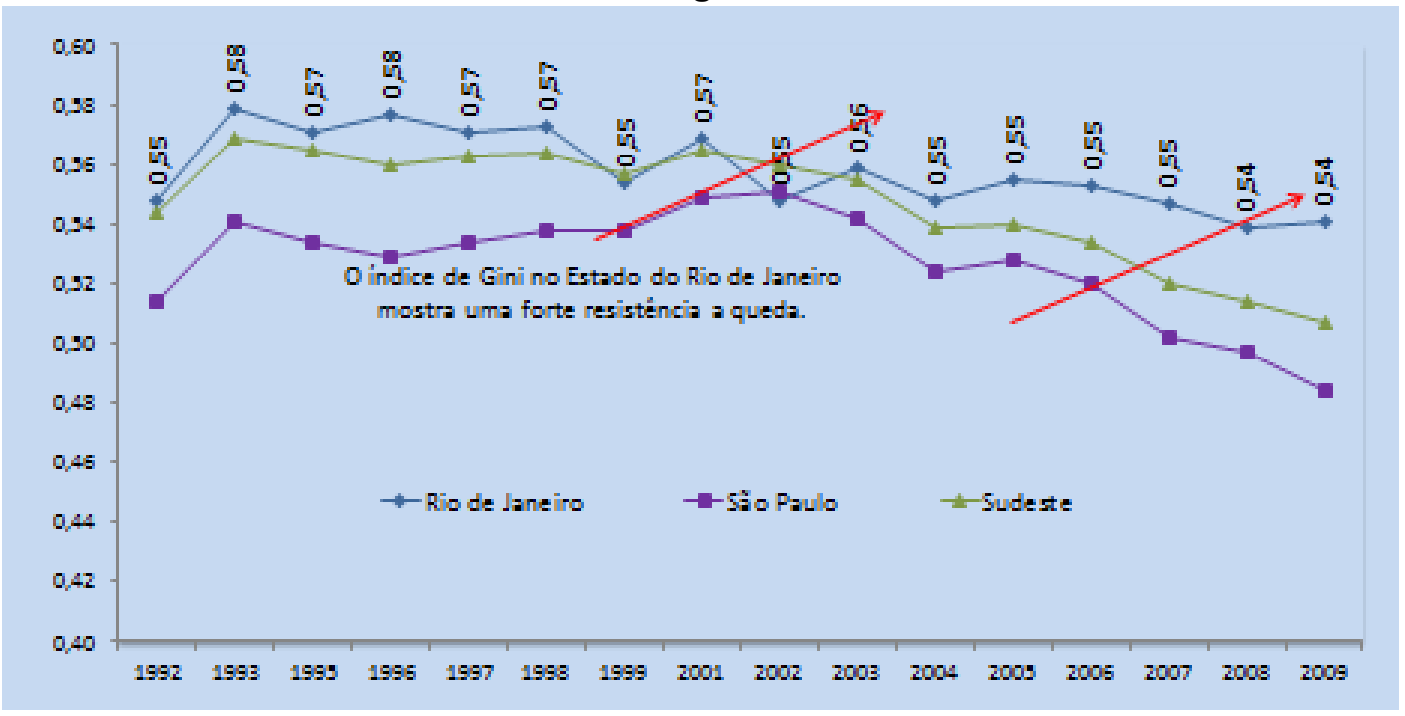

Fonte: elaboração da autora

Conforme estudos realizados por Barros (2010), em 1992 a renda per capita domiciliar média das familias cariocas era de $R \$ 569,00$, ficando o estado em 20 lugar no país, atrás somente do Distrito Federal. No ano de 2009, em nova pesquisa, a renda per capita média das famílias cariocas passou para $\mathrm{R} \$ 835,00$, registrando a queda de apenas uma posição e ficando com a terceira maior renda entre os estados brasileiros.

Gráfico 2- Evolução da renda per capita domiciliar dos estados brasileiros - 1992/2009

\begin{tabular}{|c|c|c|c|c|c|c|c|}
\hline \multirow{2}{*}{ Posição } & \multirow{2}{*}{ Estados } & \multicolumn{2}{|c|}{$\begin{array}{l}\text { Renda Domiciliar } \\
\text { Per Capita }\end{array}$} & \multirow{2}{*}{ Posição } & \multirow{2}{*}{ Estados } & \multicolumn{2}{|c|}{$\begin{array}{l}\text { Renda Domiciliar } \\
\text { Per Capita }\end{array}$} \\
\hline & & \multicolumn{2}{|c|}{1992} & & & \multicolumn{2}{|c|}{2009} \\
\hline 1 & Distrito Federal & RS & 664,00 & 1 & Distrito Federal & RS & $1.324,00$ \\
\hline 2 & Rio de Janeiro & RS & 569,00 & 2 & Santa Catarina & RS & 865,00 \\
\hline 3 & São Paulo & RS & 569,00 & 3 & Rio de Janeiro & RS & 835,00 \\
\hline 4 & $\begin{array}{l}\text { Rio Grande do } \\
\text { Sul }\end{array}$ & RS & 524,00 & 4 & São Paulo & RS & 807,00 \\
\hline 5 & Santa Catarina & R\$ & 496,00 & 5 & $\begin{array}{l}\text { Rio Grande do } \\
\text { Sul }\end{array}$ & R\$ & 774,00 \\
\hline
\end{tabular}

Fonte: elaboração da autora

Porém, se realizarmos uma análise da desigualdade de renda, iremos observar que no mesmo período houve uma queda da décima para a décima sétima posição. Ou seja, 
mesmo ampliando o PIB, isto não resultou na ampliação da renda das famílias do Estado do Rio de Janeiro, especialmente as que vivem em situação de extrema pobreza.

\begin{tabular}{|c|c|c|c|c|c|}
\hline \multirow{2}{*}{ Posiçڤ̄o } & \multirow{2}{*}{ Estedos } & \multirow{2}{*}{$\frac{\text { Indice de Gini }}{1992}$} & \multirow{2}{*}{ Posiç̄̄o } & \multirow{2}{*}{ Estedos } & \multirow{2}{*}{$\frac{\text { Indice de Gini }}{2009}$} \\
\hline & & & & & \\
\hline 9 & Rondônia & 0,545 & 9 & Minas Gerais & 0,509 \\
\hline 10 & Rio de Janeiro & 0,548 & 10 & Pará & 0,516 \\
\hline 11 & Pará & 0,549 & 11 & Mato Grosso do Sul & 0,517 \\
\hline 12 & Amazonas & 0,551 & 12 & Amapá & 0,519 \\
\hline 13 & Espirito Santo & 0,555 & 13 & Roraime & 0,521 \\
\hline 14 & Acre & 0,559 & 14 & Tocantins & 0,522 \\
\hline 15 & Minas Gerais & 0,566 & 15 & Espirito Santo & 0,528 \\
\hline 16 & Alagoas & 0,575 & 16 & Maranhão & 0,537 \\
\hline 17 & Mato Grosso do Sul & 0,581 & 17 & Rio de Janeiro & 0,541 \\
\hline 18 & Goilás & 0,581 & 18 & Ceará & 0,542 \\
\hline
\end{tabular}

Fonte: Elaboração da autora

Os estudos demonstram ainda que mesmo com a terceira maior renda per capita média entre os estados brasileiros e o segundo maior PIB dos país, de acordo com o censo IBGE (2010), mais de 586 mil pessoas ainda vivem com renda per capita inferior a $\mathrm{R} \$ 77,00^{4}$, colocando o estado em 170 no ranking das desigualdades entre os estados brasileiros.

\section{Plano Brasil Sem Miséria}

Ao lançar o PBSM, em março de 2011, o governo federal reconheceu como um dos maiores desafios a enfrentar, dentro do objetivo de erradicação da extrema pobreza, o fato de que a pobreza se caracteriza pela sua multidimensionalidade, exigindo assim uma ação articulada intersetorialmente. Apesar de o MDS desempenhar o papel principal para o cumprimento desse objetivo, compreende-se que somente será possível a execução efetiva do Plano mediante a ação integrada de um conjunto de ministérios, secretarias e órgãos de governo.

Além das premissas que definem sua forma de atuação intersetorial, o Plano prevê três frentes de ações que deverão ser executadas de forma integrada: a primeira delas

\footnotetext{
${ }^{4} \mathrm{Na}$ época da criação do Plano o corte de renda era de $\mathrm{R} \$ 70,00$ para a extrema pobreza.
} 
refere-se a elevação da renda familiar per capita daquelas famílias que se encontram em situação de extrema pobreza; a segunda concentra-se no esforço de ampliar o acesso dos mais pobres aos serviços públicos, as ações de cidadania e de bem-estar social; a terceira refere-se à execução de medidas que visam ampliar o acesso às oportunidades de ocupação e renda por meio de ações de inclusão produtiva nos meios rural e urbano.

Mediante a iniciativa do governo federal ao implantar o PBSM, que conclamou os governos subnacionais e municipais, bem como a sociedade civil em torno do objetivo civilizatório fundamental de erradicar a extrema pobreza no Brasil, o Governo do Estado do Rio de Janeiro tomou a decisão de incluir em sua agenda prioritária a elaboração de um plano estadual, o Plano Rio Sem Miséria.

\section{O Plano Rio Sem Miséria: a estratégia para a redução da pobreza no estado do Rio de Janeiro}

A execução do Plano Brasil Sem Miséria com a atuação integrada de governos subnacionais e municipais sobre a plataforma federal do Cadastro Único e PBF, complementando ações e, ao mesmo tempo, inovando em ações, de acordo com o contexto econômico e social local, como é o caso do estado do Rio de Janeiro, demonstra que política brasileira está entrando no que pode ser chamado de novo federalismo social. A participação da esfera estadual é muito importante no sentido de contribuir para ganhos de escala na implementação de políticas no bojo do PBF e demais programas, que até então refletiam uma ação direta entre o governo federal e o municipal.

É justamente neste contexto que o PRSM tem suas estruturas basilares de atuação: a partir da compreensão da necessidade de um conjunto de ações articuladas para enfrentar os múltiplos determinantes da pobreza, visto que o Plano parte da premissa de que a pobreza extrema não se refere apenas à insuficiência de renda, mas à desigualdade, composta por um conjunto de fatores dentre os quais podemos citar o desigual acesso às políticas públicas e as oportunidades sociais e econômicas, presentes nas diversas dimensões da vida das famílias e das pessoas.

O PRSM possui como objetivos específicos, de acordo com a Lei Estadual 6.088/11; i) aumentar a renda das famílias extremamente pobres para o nível além da pobreza extrema, proporcionando condições para realizar suas trajetórias de vida com maior 
autonomia e dignidade; ii) incentivar a permanência e a conclusão com qualidade do ensino médio dos jovens de famílias em situação de extrema pobreza, contribuindo para ampliar suas oportunidades de inclusão social e econômica; e iii) ampliar a inclusão social da população de baixa renda, articulando as suas capacidades e potencialidades às oportunidades econômicas e sociais (RIO DE JANEIRO, 2011).

A gestão do Plano terá a responsabilidade da Secretaria de Estado de Assistência Social e Direitos Humanos (SEASDH) e, assim como o Plano federal, terá o apoio de outras Secretarias e órgãos estaduais na sua execução, bem como da sociedade civil. Para alcançar os objetivos a que se propõe, ele é estruturado em quatro componentes: Programa Renda Melhor, Programa Renda Melhor Jovem, Gestão de Oportunidades Econômicas e Sociais, Fortalecimento do Sistema Único de Assistência Social (SUAS) e Acompanhamento Familiar, que passaremos a detalhar a seguir.

\section{Programa Renda Melhor - PRM}

O PRM é um programa de transferência de renda destinado às famílias que já são beneficiárias do PBF e que possuem renda per capita mensal estimada inferior a $\mathrm{R} \$ 100,00$.

O valor do benefício a ser pago às famílias é calculado de acordo com a severidade de pobreza de cada núcleo familiar, em particular, a partir do conjunto de informações contidas no Cadastro Único, declarada por esse, visto que as informações contidas são autodeclaratórias, sem a necessidade de comprovação. É a chamada renda estimada, uma inovação trazida pelo Programa, que leva em consideração as características estruturais que melhor expressam as condições de extrema pobreza das famílias, originadas pela renda, mas que no seu conjunto são oriundas de fatores que perpassam a renda, ou seja, expressam um conjunto de desigualdades sociais e econômicas, além de permitir uma seleção mais adequada das famílias, ao considerar suas individualidades e particularidades.

O Programa tem como objetivos principais: i) elevar a renda das famílias beneficiárias do PBF de forma que essas superem a linha de extrema pobreza definida no âmbito do Rio de Janeiro; ii) proporcionar às famílias beneficiárias condições para que realizem suas trajetórias de vida com maior autonomia e dignidade; e iii) contribuir para a dinamização das economias locais, em particular das localidades que concentram maiores taxas de extrema pobreza. 
Para atingir os objetivos de reduzir a extrema pobreza monetária, por meio do PRM, é repassado um valor monetário às famílias que varia de $\mathrm{R} \$ 30,00$ a $\mathrm{R} \$ 300,00$. 0 pagamento desse valor é efetuado por meio de cartão compartilhado, contendo a identidade visual do PBF e do PRM, utilizando a mesma rede ${ }^{5}$ e obedecendo ao mesmo calendário de pagamento do PBF. Atualmente, de acordo com a SEASDH, mais de 200 mil famílias são beneficiárias do Programa, com um valor mensal de repasse de $\mathrm{R} \$ 22$ milhões.

As condicionalidades do PRM são as mesmas do PBF, e o seu acompanhamento é um reforço ao direito e garantia de acesso das famílias aos serviços básicos de saúde, educação e assistência social. Caso uma situação de descumprimento seja identificada, o sistema de proteção social é acionado para tomar as medidas necessárias para que o acesso aos direitos seja reestabelecido.

No ano de 2011, os municípios de Japeri, Belford Roxo e São Gonçalo foram incluídos no PRM na modalidade de implantação piloto. Esses municípios foram priorizados como piloto porque estão na Região Metropolitana e possuem baixos índices de desenvolvimento, bem como elevado contingente populacional. Em 2012, mais 48 municípios ingressaram no Programa e, em 2013, alcançou-se a cobertura total ${ }^{6}$ do PRM nos municípios do estado. Em conformidade com a diretriz de cooperação federativa, estado e municípios assinaram um termo de adesão com os compromissos e responsabilidades de cada ente.

\section{Programa Renda Melhor Jovem}

O Programa Renda Melhor Jovem (PRM) é uma estratégia muito importante do PRSM, e tem como objetivos: i) promover o desenvolvimento dos jovens, com foco na erradicação da pobreza extrema por meio do investimento em capital humano; ii) incentivar a permanência e bom desempenho do jovem na escola; iii) contribuir para o aumento das taxas de aprovação e conclusão do ensino médio no Estado do Rio de Janeiro; e iv) contribuir para a redução dos determinantes das vulnerabilidades da juventude.

\footnotetext{
${ }^{5}$ Utiliza a rede de pagamento da Caixa: agências, lotéricas e correspondentes bancários.

60 município do Rio de Janeiro não é atendido pelo PRM, possuindo um programa próprio, o Programa Cartão Família Carioca.
} 
O Programa é executado por meio de uma parceria entre a SEASDH e a Secretaria de Estado de Educação (SEEDUC), sendo destinado aos jovens que ingressem com até 18 anos no $1^{\circ}$ ano do ensino médio e façam parte de famílias beneficiárias do Programa Bolsa Família e do Programa Cartão Família Carioca (para os beneficiários do município do Rio de Janeiro) ou do Programa Renda Melhor (para os jovens dos demais municípios). É necessário estar matriculado na Rede Estadual de Ensino Médio Regular (incluindo os Ensinos Normal, Médio Integrado e Profissionalizante concomitante). Prevê como prêmio uma poupança anual por sua aprovação no ensino médio. Para receber os benefícios, os jovens precisam ser aprovados e concluir o ensino médio.

O jovem inscrito no PRM receberá um valor a ser depositado em conta poupança no Banco do Brasil, condicionado a sua aprovação, com os seguintes valores: $R \$ 700,00$ na $1^{\circ}$ série do ensino médio; $R \$ 900,00$ na $2^{\circ}$ série do ensino médio; $R \$ 1.000,00$ na $3^{\circ}$ série do ensino médio; $\mathrm{R} \$ 1.200,00$ no ensino médio profissionalizante de 4 anos; e prêmio de Conclusão Qualificada de $\mathrm{R} \$ 500,00$ ao final do ensino médio, caso obtenha um bom desempenho no ENEM.

Os jovens têm o direito de sacar até $30 \%$ do valor recebido anualmente, e o saldo dos benefícios acumulados ao longo dos anos ficará depositado na poupança do Banco do Brasil, tendo a sua correção financeira garantida. O valor acumulado ao longo dos anos somente poderá ser sacado se o jovem concluir o ensino médio. Se o jovem for excluído do Programa (reprovação, desistência ou aprovação com dependência entre outros), o recurso acumulado na poupança não será passível de saque.

O PRMJ teve início em julho de 2011 com o projeto piloto nos municípios de Japeri, Belford Roxo e São Gonçalo. Em 2012, foi expandido para 49 municípios e, em 2013, para 40, atingido cobertura total no estado ${ }^{7}$, com 40.943 jovens elegíveis para o ano de 2014.

\section{Gestão de Oportunidades Econômicas e Sociais}

Uma terceira estratégia do PRSM é a Gestão de Oportunidades Econômicas e Sociais, que tem como objetivo aproximar as pessoas que vivem em condição de extrema pobreza

\footnotetext{
${ }^{7}$ O PRMJ contempla os jovens do município do Rio de Janeiro, cujas famílias são beneficiárias do Programa Cartão Família Carioca.
} 
com as oportunidades econômicas e sociais, reduzindo assim a assimetria e a distância de acesso a essas oportunidades.

Esta estratégia tem como premissas: i) intensivo em formação, objetivando a inserção no mundo do trabalho; ii) coordenação entre as diversas esferas do governo e atores da sociedade civil e da iniciativa privada; iii) especificidade do Estado como articulador; e iv) institucionalização da Gestão.

Para que o GOES seja implementado, o Estado assume protagonismo na pactuação e articulação federativa no combate à miséria. Devido a proximidade e o conhecimento das realidades locais, o Estado mune-se de capacidade técnica e operacional para, articulado com os municípios, conhecer as demandas e potenciais de famílias em situação de extrema pobreza, aproximando-as das ofertas de cada território. Ou seja, a estratégia não consiste apenas em mapear a oportunidades existentes, mas em aproximar tais famílias e contribuir para as que possam acessar essas oportunidades. O público-alvo são as famílias do PRM e os jovens do PRMJ. Os objetivos da estratégia consistem em: i) conhecer e sistematizar o perfil socioeconômico da população em situação de vulnerabilidade (extrema pobreza); ii) mapear e induzir as ofertas de políticas e de oportunidades econômicas; e iii) reduzir a assimetria de oportunidades, aproximando os mundos da extrema pobreza ao dinamismo econômico.

A metodologia da estratégia consiste no mapeamento de demandas e potencialidades, reuniões nos Centros de Referências em Assistência Social (CRAS) com os técnicos da Assistência Social e as famílias e com as lideranças locais, mobilização de parceiros e apresentação e discussão do cardápio de ofertas sociais e econômicas ao município (sociedade civil e poder público), conforme podemos observar na figura baixo.

Figura 2- Metodologia do GOES

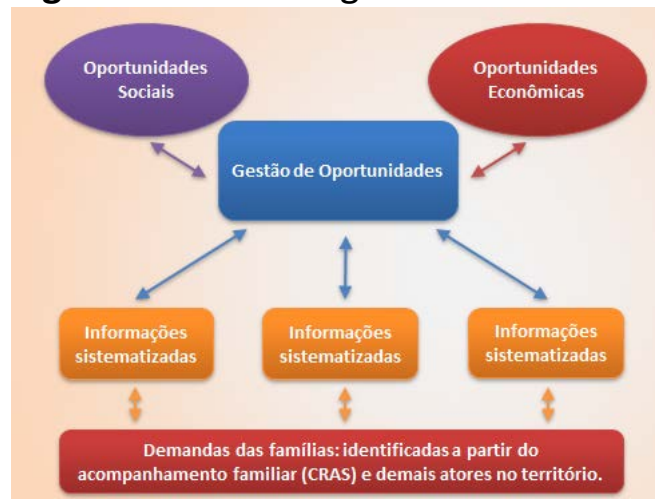

Fonte: elaboração da autora 
Compõem os atores do território o poder público (federal, estadual e municipal), a iniciativa privada, a sociedade civil e as lideranças formais e informais nos territórios. Já os parceiros são o poder público, as fundações públicas e privadas, ONG's e organismos e parceiros internacionais.

Atualmente, são desenvolvidas ações com os seguintes parceiros: SINDUSCON/SECONCI - cursos construção civil; CIEE - cursos iniciação ao trabalho; ITC cursos para cuidadores de idosos; BANCO DO BRASIL - RMJ e orientação financeira; INVESTE RIO - oferta de microcrédito preferencial; COCA COLA/Mc DONALD'S - varejo para jovens do RMJ; CORREIOS - emissão de CPF para os alunos do RMJ; LOREAL/ SEBRAE cursos técnicos, empreendedorismo e vendas; e METRO RIO - oportunidades de trabalho.

\section{Acompanhamento familiar e Fortalecimento do SUAS}

Com a adesão dos municípios ao Plano Rio Sem Miséria, este também assume o protagonismo na execução das ações por meio do acompanhamento familiar e da busca ativa para a inclusão das famílias no Cadastro Único. Nesse sentido, o fortalecimento da rede socioassisntencial do SUAS é vital para o fortalecimento, a execução e o sucesso do Plano.

A atuação da equipe de Assistência Social, bem como a construção de ações intersetoriais, como a saúde e a educação, são fundamentais em função do conhecimento do território, bem como das condições da realização da interlocução direta e do acompanhamento sistemático com as famílias em situação de extrema pobreza.

O papel do Estado nesta estratégia consiste em oferecer aos municípios assessoramento técnico, capacitação contínua e cofinanciamento (como, por exemplo, a expansão de CRAS e CREAS) e o fortalecimento da ação técnica efetuada pelos municípios, objetivando o fortalecimento da potencialização para o atendimento das demandas às famílias no processo de alcance das seguranças sociais.

\section{Conclusões}

O objetivo da pesquisa consistiu em analisar a contribuição do PRSM para a construção das políticas de proteção social no Estado do Rio de Janeiro, com vistas a redução da pobreza. 
Este estudo permitiu, sem a pretensão de esgotar o tema, a possibilidade de pontuarmos algumas evidências fundamentais que podem ser consideradas potencialidades do Plano, para o combate à pobreza e à desigualdade, implicando melhorias das condições de vida e renda das famílias beneficiárias e outros elementos aqui denominados desafios futuros, os quais podem ser considerados desafios para o combate à desigualdade e para o próprio PRSM.

Em termos de potencialidades podemos citar:

- É uma experiência exitosa no que se refere ao novo modelo de políticas públicas adotados no Brasil: o novo federalismo social, em que o governo subnacional atua de maneira integrada sobre a plataforma do Cadastro Único, complementando e inovando em ações executadas nos programas;

- Outro aspecto extremamente relevante e inovador é a utilização do conceito de renda estimada, em que não se utiliza a informação da renda monetária declarada pelas famílias, mas sim um conjunto de informações contidas no Cadastro Único, em que é possível capturar a situação individual das famílias, colocando-a na centralidade para que essa receba o benefício de acordo com a sua situação não apenas de insuficiência de renda, mas de desigualdade a que é submetida;

- A articulação com o PBF permitiu aos beneficiários do PRM que possuem as mesmas condicionalidades reforço na garantia de direitos e acesso aos serviços de saúde, educação e assistência social;

- O Programa Renda Melhor Jovem oferece a oportunidade e incentivo aos adolescentes e jovens para ingressarem, permanecerem e concluírem o ensino médio, por meio de prêmios, e assim elevar o índice de jovens concluintes do ensino médio, das famílias extremamente pobres. Este fato implica a redução de desigualdade entre os mais pobres por meio do acesso à educação;

- A busca ativa foi uma importante estratégia adotada para a ampliação da cobertura cadastral no Estado do Rio de Janeiro. Em 12 meses, o número de famílias cadastradas no estado passou de 1.331.127 para 1.508.226, representando um amplo crescimento e compromisso das gestões municipais com estratégia e com o Plano. 
Como desafios futuros para o Plano, entendemos que sejam:

- O atendimento a todas as famílias em situação de extrema pobreza ainda é um desafio, ou seja, é necessário que todo o público-alvo do Plano seja alcançado em todas as estratégias para que a universalização seja plenamente atingida. Como exemplo, citamos o PRMJ, quando observamos na pesquisa que nem todos os jovens com perfil de elegibilidade para o Programa estão inseridos, por problemas operacionais;

- A focalização precisa ser compreendida como progressiva, tendo em vista a se atingir a universalização relativa ao público definido pelos critérios de elegibilidade do Plano;

- Para cumprir os fins a que se propõe, o Plano deve ampliar a cobertura não apenas para as famílias em situação de extrema pobreza, mas para aquelas famílias pobres e que conviveram com uma longa história de pobreza. A renda estimada é um avanço, mas é necessário ampliar o recorte de renda;

- A Gestão de Oportunidades Econômicas e Sociais (GOES) ainda é uma estratégia que carece de ampliação, ou seja, as oportunidades ofertadas às famílias são limitadas, descontínuas e insuficientes, tanto no que se refere à qualificação profissional como para os encaminhamentos ao mercado de trabalho, além dos limites do próprio mercado de trabalho, que é incapaz de absorver toda a população apta;

- A responsabilidade pela execução do Plano nos municípios é de responsabilidade da política de assistência social. Não houve uma discussão para a construção e o planejamento de uma agenda coletiva com os Gestores Municipais. Em função disso, acorrem algumas situações em que o funcionamento do Plano não é compreendido e apreendido pelas Gestões Municipais;

- A ausência de articulação entre os diversos segmentos públicos e privados envolvidos na gestão do Plano reforça a necessidade da construção de uma agenda conjunta de fato, evitando ações replicadas nos mesmos territórios em 
detrimento a não execução de ações em territórios com elementos de extrema vulnerabilidade;

- Centralidade no quadro de pessoal nos municípios, onde de fato o Plano é executado, visto que há atendimento direto às famílias. Identificamos a insuficiência quantitativa, a instabilidade e a capacitação deficiente para o desenvolvimento de trabalhos requeridos pela alta complexidade, em grande número devido à rotatividade dos servidores;

- O fortalecimento do SUAS ainda é um grande desafio para a política de assistência social. Em função da grande demanda incorporada e atrelada a esta, o número de equipamentos sociais e sua estrutura física e de pessoal está longe de atender às demandas e às necessidades da população;

- O acompanhamento familiar ainda é uma agenda que precisa ser priorizada tanto pela Gestão Estadual como pela Gestão Municipal do PBF e do PRSM, objetivando o acompanhamento das famílias em situação de vulnerabilidade;

- A criação e o fortalecimento de uma rede na esfera estadual, municipal e com a sociedade civil constituem-se um dos principais desafios para que PRSM consiga alcançar os seus objetivos de maneira eficiente e eficaz.

Com a consolidação de parte das estratégias que compõem o Plano (PRM e PRMJ) pela focalização, é necessário, no entanto, o fortalecimento das demais estratégias e a expansão das políticas protetivas, para a inclusão dessas famílias num sistema de proteção social mais amplo e integrado, capaz de lidar com o que hoje visivelmente não consegue: os riscos e as incertezas.

O Estado tem a função precípua de provedor das políticas públicas com a finalidade do enfrentamento da questão social, no sentido de criar mecanismos para a diminuição dos impactos das relações fragilizadas no âmbito do trabalho que origina indivíduos com vulnerabilidades sociais oriundas da relação de exploração advinda do sistema capitalista. Sistema esse é cerne da questão social, e o Plano Rio Sem Miséria é uma estratégia recente, inovadora, atual conjuntura social e econômica do Estado do Rio de Janeiro, com muitos avanços aqui registrados, e pode ser considerado fundamental pelos efeitos que tem produzido na redução da desigualdade e da pobreza e, mais ainda, pelo potencial que possui para ampliar esses efeitos. 


\section{Referências}

BANCO MUNDIAL. O trabalho e o processo de integração mundial. Washington: BIRD,1995.

BARROS, R. P. "Cenários da pobreza e da fome no Brasil". In: SESC Rio de Janeiro. (Org.). "Anais Seminário Nacional Mesa Brasil SESC". Rio de Janeiro: Serviço Social do Comércio, 2010, v. 1, p. 38-45.

BRASIL. Constituição da República Federativa do Brasil de 1988. Disponível em: <http://www.planalto.gov.br/ccivil_03/Constituicao/Constituicao.htm>. Acesso em: 11 dez. 2015.

BRASIL. Ministério de Desenvolvimento Social e Combate à Fome. Informações sociais. Brasília: MDS, 2014.

CASTEL, R. As metamorfoses da questão social:uma crônica do salário. Petrópolis: Vozes, 1998.

CEPERJ - FUNDAÇÃO CENTRO ESTADUAL DE ESTATÍSTICAS, PESQUISAS E FORMAÇÃO DE SERVIDORES PÚBLICOS. Anuário RJ 2013. Rio de Janeiro, 2014. Dipsonivel em:

$<$ http//www.ceperj.gov.brz. Acesso em: 10 dez. 2014.

DI GIOVANNI, G. Sistema de proteção social: uma introdução conceitual. In: OLIVEIRA, M. A. (Org.). Reforma do estado e políticas de emprego no Brasil. Campinas: UNICAMP, 1998.

DRAIBE, S. As políticas sociais e o neoliberalismo: reflexões suscitadas pelas experiências latino-americanas. Revista da USP, São Paulo, v. 17, p. 86-101, 1993.

ESPING-ANDERSEN, G. As três economias políticas do Welfare State. Lua Nova, São Paulo, n. 24, p. 85-116, 1991.

IBGE. CENSO DEMOGRÁFICO 2010. Características da população e dos domicílios: resultados do universo. Rio de Janeiro: IBGE, 2011. Acompanha 1 CD-ROM. Acesso em: dez. 2014.

JACCOUB, L.; CARDOSO JUNIOR, J. C. Políticas sociais no Brasil: organização, abrangência e tensões da ação estatal. In: JACCOUD, L. (Org.). Questão social e políticas sociais no Brasil contemporâneo. Brasília: IPEA, 2010. p. 181-260.

PEREIRA, P. A. P. Pluralismo de bem-estar ou configuração plural da política social sob o Neoliberalismo. Política Social. Brasília, n. 2, p. 135-160, 2000.

RIO DE JANEIRO. Lei no 6.088, de 25 de novembro de 2011. Cria os programas renda melhor e renda melhor jovem, no âmbito do plano de superação da pobreza extrema do Estado do 
Rio de Janeiro - rio sem miséria -, e dá outras providências. Disponível em: <http://govrj.jusbrasil.com.br/legislacao/1030211/lei-6088-11>. Acesso em: 11 nov. 2015.

SEASDH. Manual do Programa Renda Melhor. 2014a.

SEASDH. Manual do Programa Renda Melhor Jovem. 2014b.

SPOSATI, A. O. et al. Direitos sociais: afinal do que se trata? Belo Horizonte: UFMG, 2009.

TELLES, Vera da Silva. No fio da navalha: entre carências e direitos. Notas a propósito dos programas de renda mínima no Brasil. In: CACCIA-BAVA, Silvio (org.)."Programas de Renda Mínima no Brasil”. Cadernos Polis. no. 30: 1-24. São Paulo, Pólis, 1998

VIANA, A. L. D'Á.; LEVCOVITZ, E. Proteção Social: introduzindo o debate. In: VIANA, A. L. D'Á.; ELIAS, E. M.; IBAÑEZ, N. (Org.). Proteção social: dilemas e desafios. São Paulo: Hucitec, 2005.

Recebido em: 31/10/2015

Aprovado em: 06/12/2015 